\title{
A LIBERDADE DISCURSIVA EM HABERMAS E AS INFLUËNCIAS DO ABUSO DE
} PODER ELEITORAL

\author{
Antonio Carlos Suppes Doorgal de Andrada ${ }^{1}$ \\ Alex da Silva Alvarenga ${ }^{2}$
}

\section{RESUMO:}

O presente artigo tem por objetivo promover o exame do instituto do abuso de poder tangente ao processo eleitoral, lato sensu, como interferência na chamada autonomia pública, introduzida por Jürgen Habermas no seu texto "Direito e Democracia", bem como a analisar como deve ser institucionalizado o princípio do discurso a fim de que o processo de formação da vontade do Estado se torne independente de influências externas que possam interferir no auto-reconhecimento da população como partícipe desse processo.

Palavras-chave: Habermas; Direito Eleitoral; Democracia; Discurso; Abuso de poder

\section{THE DISCURSIVE FREEDOM IN HABERMAS AND THE INFLUENCES OF THE ABUSE OVER THE ELECTORAL PROCESS}

\begin{abstract}
:
This article intends to explore the power abuse over the electoral process, lato sensu, as an interference point under Jürgen Habermas concept of public autonomy, described in his Law and Democracy textbook, and also to analyze how the principle of discourse should be institutionalized so that the process of formation of the state identity can be independent of external influences that may interfere in the population self-recognition as a participant in this process.
\end{abstract}

Keywords: Habermas; Electoral law; Democracy; Discourse; Power Abuse

\section{INTRODUÇÃO}

O sistema político-representativo, adotado pela maioria dos países democráticos ocidentais tem sido objeto de amplo debate na filosofia política. Há anos diversos autores, como John Locke e Jean Jacques-Rousseau, têm apresentado concepções diversas dos modelos que compreendem como o mais democrático, ou seja, capaz de, legitimamente representar a vontade popular.

\footnotetext{
${ }^{1}$ Mestrando em Direito nas Relações Econômicas e Sociais pela Faculdade de Direito Milton Campos

${ }^{2}$ Mestrando em Direito nas Relações Econômicas e Sociais pela Faculdade de Direito Milton Campos
}

Revista de Teorias da Democracia e Direitos Políticos | e-ISSN: 2525-9660 | Brasília | v. 3 | n. 1 | p. 23 - 38 | Jan/Jun. 2017. 
Ocorre que referidas teorias políticas não levaram em conta os diversos fatores externos capazes de atingir o grau de representatividade da população nas câmaras legislativas e no próprio poder executivo.

No presente artigo, abordar-se-á a concepção habermasiana de democracia e como o abuso de poder político e econômico pode vir a influenciar negativamente no modelo democrático proposto pelo autor.

Para tanto, será feita uma introdução ao pensamento de Jürgen HABERMAS, com apresentação de seus conceitos básicos sobre democracia. No capítulo seguinte, serão tecidas considerações a respeito do abuso de poder eleitoral e como tal tema é tratado no direito brasileiro.

Em seguida, no terceiro capítulo, será discutido como o abuso de poder influencia negativamente no processo eleitoral, resultando em um déficit democrático. Por fim, será apresentada conclusão, em que se discutirá se o direito brasileiro dispõe de elementos suficientes e aptos a combater afigura do abuso de poder praticado durante o pleito eleitoral.

\section{BREVES CONSIDERAÇÕES AO PENSAMENTO HABERMASIANO}

Jürgen Habermas é, reconhecidamente, um dos mais respeitados sociólogos e filósofos da atualidade. Oriundo da escola de Frankfurt, o intelectual tem pautado discussões acerca de temas de relevância ímpar para a sociedade como um todo. Suas teorias têm revelado falhas importantes na democracia praticada em todo o mundo, notadamente, no Brasil, e apontam para a necessidade de se adotar o discurso racional como um instrumento potencializador do princípio democrático.

Com efeito, em seus textos, identifica-se uma postura propositiva, não se limitando o filósofo a descrever o problema, mas também a sugerir mudanças de comportamento social. Segundo HABERMAS (2012, p. 113), "uma teoria crítica da sociedade não pode limitar-se a uma descrição da relação entre norma e realidade, servindo-se apenas da perspectiva do observador".

Em Direito e Democracia, HABERMAS explora a formação dos direitos subjetivos, que definem basicamente o espaço de liberdade de atuação de cada um dos indivíduos sociais, dentro dos quais o autor insere os chamados "direitos políticos". Assim afirma o autor em sua obra: 
Mesmo sem levar em conta as diferenças nas modalidades de uso desses direitos, os direitos políticos também devem poder ser interpretados como liberdades de ação subjetivas, as quais simplesmente fazem do comportamento legal um dever, portanto liberam os motivos para um comportamento conforme as regras. (HABERMAS, 2012, p. 115).

O que se percebe, portanto, é que os direitos políticos são, na visão habermasiana, responsáveis por definirem os cidadãos como sujeitos aptos a participarem do processo de formação das leis - o que, no Brasil, se concretizaria pelo sistema representativo disposto na Constituição, viabilizado pelas eleições diretas.

Sobre o processo legiferante, HABERMAS (2012, p. 157). aponta, recorrendo a Kant, que "A ideia da autolegislação de civis exige que os que estão submetidos ao direito na qualidade de destinatários, possam entender-se também enquanto autores do direito".

Trata-se do reconhecimento ou ainda, de um critério de julgamento de validade normativa, segundo o qual a lei é reconhecida como tal quando os sujeitos a que se dirigem conseguem se identificar como participantes do processo de sua criação, o que ocorre por meio da implementação do discurso livre e acessível a todos durante o processo de inovação normativa, ou seja, por meio de um procedimento eminentemente racional, em superação aos tradicionais modelos liberal e republicano (HABERMAS, 2004, p. 53).

Como se vê, o autor resgata o modelo democrático em que a representatividade dos cidadãos e o seu acesso ao processo de formação das leis é não só facilitado, mas constitui um pressuposto de legitimidade legislativa que deve ser institucionalizado. Em análise sobre a teoria de HABERMAS, o professor Jorge Adriano LUBENOW (2010) esclarece que:

O princípio procedimental da democracia visa amarrar um procedimento de normatização (o que significa: um processo de institucionalização da formação racional da opinião e da vontade), através do caráter procedimental, que garante formalmente igual participação em processos de formação discursiva da opinião e da vontade e estabelece, com isso, um procedimento legítimo de normatização. (LUBENOW, 2010, p.1)

De fato, a preocupação de HABERMAS em institucionalizar o discurso participativo no âmbito da democracia participativa visa justamente garantir a higidez da atuação dos representantes do povo nas câmaras legislativas, travando assim um combate natural ao abuso de poder econômico e político, principais fatores de influência externa ao princípio democrático. Segundo LUBENOW (2010): 
As implicações normativas são evidentes: a força sociointegrativa da solidariedade, que não pode mais ser obtida, mas ser extraída apenas das fontes da ação comunicativa, precisa desenvolver-se em espaços públicos autônomos diversos e procedimentos de formação democrática da opinião e da vontade política institucionalizados jurídico-estatalmente; e ser capaz de se afirmar contra os outros dois poderes, dinheiro e poder administrativo. (LUBENOW, 2010, p.1)

Ocorre que, a simples elaboração de um rito procedimental que garanta a ampla participação popular na formação de vontade do estado não é suficiente para assegurar a elaboração de um bom arcabouço normativo nacional. Sobre esse ponto de tensão, Aulis AARNIO (2011) sustenta que o processo de justificação externa de uma locução deve sim ser regido por etapas - o que o autor chama de D-rational discourse -, mas esse processo deve também gerar um resultado razoável:

The external justification can also be characterized as a form of a contextually sufficient one. It is contextually sufficient because it only deals with material that is accepted as legal. The interpreter does ask why this type of sources of law must, should or can be used. Or why these rules of interpretation are to be followed. He simply justifies the interpretation in the same way as jurists usually put forward their arguments. The interpreter makes his moves within the given legal framework following the rules of D-rationality.

However, the interpretation also has to fulfill certain of material rightness - i.e., acceptability in the legal community in question. Interpretations must be based on D-rational discourse but, in addition to that, the result of the discourse must be reasonable. Providing these conditions are satisfied, the result is rationally acceptable in the community. It is both rational and reasonable. (AARNIO, 2011, p. 135$)^{3}$

Dessa forma, clara é a posição de HABERMAS (2004, 2012) no sentido de que devem ser criados mecanismos jurídicos institucionalizados que possam assegurar o amplo discurso no âmbito do processo de formação democrática da opinião e da vontade dos cidadãos, o que

\footnotetext{
${ }^{3}$ Tradução nossa: "A justificação externa também pode ser caracterizada como uma forma de justificação contextualmente suficiente. É contextualmente suficiente porque trata apenas de material aceito como legal. O intérprete pergunta por qual motivo este tipo de fonte de direito deve ou pode ser utilizado. Ou por que essas regras de interpretação devem ser seguidas. Ele simplesmente justifica a interpretação da mesma maneira que os juristas costumam apresentar seus argumentos. $\mathrm{O}$ intérprete faz seus movimentos dentro do quadro legal dado seguindo as regras da racionalidade D.

No entanto, a interpretação também tem de cumprir certo grau de justificação material - ou seja, a aceitabilidade na comunidade jurídica em questão. As interpretações devem ser baseadas no discurso racional-D, mas, além disso, o resultado do discurso deve ser razoável. Desde que essas condições sejam satisfeitas, o resultado é racionalmente aceitável na comunidade. É racional e razoável".
} 
atrelada à racionalidade descrita no pensamento de AARNIO (2011), seria suficiente a conferir maior legitimidade ao nosso poder legislativo.

\section{O ABUSO DE PODER E O DÉFICIT DEMOCRÁTICO}

Feitas as considerações introdutórias, percebe-se a importância dada por HABERMAS (2004, 2012) à criação de um sistema normativo que potencialize e garanta a participação autônoma e independente dos cidadãos no processo de criação normativa, de forma a protegêlo dos abusos políticos e econômicos aptos a interferirem na autonomia discursiva travada no Poder Legislativo, até porque, nas palavra de Said MALUF (2006, p. 225), se o poder emana do povo, "nenhum poder pessoal poder sobrepor-se à vontade geral".

É justamente sobre o abuso de poder praticado no período eleitoral e as suas influências sobre o discurso democrático que irá se debruçar, tendo em vista que "somente a normatização politicamente autônoma permite aos destinatários do direito uma compreensão correta da ordem jurídica em geral" (HABERMAS, 2012, p. 156).

O abuso de poder no âmbito do Direito Eleitoral pode ser classificado como instrumento dirigido a corromper o eleitor por meio da oferta de vantagens econômicas ou políticas em troca de seu voto. O Tribunal Superior Eleitoral (2016) tem subdividido tradicionalmente o instituto em dois tipos: o abuso de poder político e o abuso de poder econômico. Segundo a Corte Superior Eleitoral, em voto de lavra do Ministro Gilmar Mendes:

Consoante a jurisprudência deste Tribunal Superior Eleitoral, o abuso do poder político caracteriza-se quando determinado agente público, valendo-se de sua condição funcional e em manifesto desvio de finalidade, compromete a igualdade da disputa eleitoral e a legitimidade do pleito em benefício de sua candidatura ou de terceiros (...) (Recurso Ordinário 466997 - Curitiba/PR)

Por outro lado, o abuso de poder econômico é conceituado como aquele que se caracteriza pelo "emprego desproporcional de recursos patrimoniais (públicos ou privados), ambos de forma a comprometer a legitimidade do pleito e a paridade de armas entre postulantes a cargo eletivo" (Agravo no Recurso Especial Eleitoral n 10070, Paulínia/SP TSE). CASTRO (2014) concorda com a divisão, e conceitua os diferentes tipos de abuso da seguinte forma: 
O abuso de poder econômico nada mais é do que a transformação do voto em instrumento de mercancia. É a compra, direta ou indiretamente, da liberdade de escolha dos eleitores.

Tivemos a oportunidade de dizer que a propaganda eleitoral destina-se ao debate de ideia entre candidatos, visando a que os eleitores sejam amplamente informados a respeito dos futuros homens público em que aqueles pretendem transformar-se. E ninguém nega que uma campanha eleitoral exige gastos, exige uso do dinheiro. Nada de anormal até aí, mesmo porque a própria lei regulamenta a captação de recurso para o financiamento das campanhas.

Entretanto, quando os candidatos resolvem utilizar-se do poder econômico, não como forma de viabilizar a campanha, mas como principal fonte do convencimento dos eleitores, caracteriza-se o abuso (CASTRO, 2014, p. 285/286).

(...)

O agente público, ou seja, aquele que detém o exercício de uma função pública, coloca-se em situação de vantagem perante o "cidadão comum", porque tem como atividade cotidiana o atendimento dos interesses da coletividade e porque está naturalmente em evidência. Sem qualquer esforço, pode conquistar a simpatia dos que buscam o serviço púbico, bastando que cumpra com presteza o seu mister. Então, sem necessidade de se falar em abuso, o exercente de função pública já tem posição de destaque no contexto social, principalmente nos centros menores.

A verdade é que esses agentes públicos, em período eleitoral, acabam se utilizando da sua posição de destaque para beneficiar candidatura. (...) Esses atos de governo/administração, em outras ocasiões até entendidos lícitos, podem caracterizar abuso do poder político, porque assumem finalidade eleitoreira. (CASTRO, 2014, p. 304).

No mesmo sentido, GOMES (2016, p. 311/312) preceitua que "haverá abuso sempre que, em um contexto amplo, o poder - não importa sua origem ou natureza - for manejado com vistas à concretização de ações irrazoáveis, anormais, inusitadas ou mesmo injustificáveis diante das circunstâncias que se apresentarem". Por tais razões, considerando a amplitude do abuso de poder no Direito Eleitoral, seu combate deve ser amplo, de modo a "cobrir todos os flancos, escudando-se nos mananciais da ordem, seja para impedir as manifestações opressivas do poder com dano para a liberdade, seja também a não permitir que esta degenere com exorbitâncias possessiva", conforme nos ensina RIBEIRO (2001, p. 21).

O combate ao abuso do poder ganha especial relevância no Estado Democrático de Direito, em que a Constituição, segundo leciona MELLO (2011, p. 11), “não é mero ideário. Não é apenas expressão de anseios, de aspiração, de propósitos. É a transformação de um ideário, é conversão de anseios e aspirações em regras impositivas. Em comando. Em preceitos obrigatórios para todos: órgão do Poder e cidadãos".

Ora, se a própria Constituição dispõe que o poder emana do povo, que o exerce por meio de seus representantes eleitos, é preciso que se estabeleçam critérios de combate ao abuso de poder, em especial por parte dos agentes públicos que atuam em nome do Estado, de forma a garantir a isonomia dos participantes nos pleitos eleitorais, frequentemente 
inobservada na vida política brasileira, em que, com frequência, "a autoridade pratica um ato administrativo movido pela amizade ou inimizade, pessoal ou politica, ou até em proveito próprio" (MELLO, 2012, p. 62). Melhor explica o autor:

\begin{abstract}
A vida administrativa brasileira, desgraçadamente, pode oferecer inúmeros exemplos desta nefanda modalidade de desvio de poder, muito comum por razões sectárias. Tanto assim é, que se põe - como comprovação indireta - a contingência legislativa de vedar, drasticamente, admissões, exonerações e remoções ex officio no período eleitoral. Ha nisto um explícito reconhecimento de que ditas práticas, sobremodo vitandas, existiriam aos bolhões não fora pelas cautelas legislativas. Se estas não conseguem evita-las, ao menos restringir em parte suas ocorrência. Coibindo-as liminarmente nas épocas em que os ânimos políticos estão mais encandecidos, guardam a expectativa (tantas vezes frustrada) de que, fora deles, com o arrefecimento das paixões sectárias, os administradores se façam mais contidos (MELLO, 2012, 62/63).
\end{abstract}

Neste contexto, havendo conduta que interfira na legitimidade do pleito eleitoral, é preciso que seja combatida. É o que se pode extrair dos conceitos jurisprudenciais citados, em que há um ponto de intercessão entre as duas formas de abuso de poder: ambas exigem que a conduta tenha sido suficiente a comprometer a legitimidade do pleito e a igualdade da disputa eleitoral. Vale dizer, quando a jurisdição eleitoral incide sobre casos concretos de abuso de poder, busca-se sempre demonstrar que a conduta praticada pelo candidato delituoso desequilibrou o processo de escolha dos agentes políticos que irão representar os eleitores, o que constitui a denominada potencialidade lesiva da conduta.

Não obstante, quando a figura do abuso de poder praticado em campanhas eleitorais não é levada ao conhecimento do poder judiciário - o que, diante da insuficiência do aparato fiscal estatal, é corriqueiro - instala-se um verdadeiro déficit na representação democrática popular na formação da vontade do Estado. Segundo o TRE-MS:

RECURSO ELEITORAL. AÇÃO DE IMPUGNAÇÃO DE MANDATO ELETIVO. ALEGAÇÃO DE ABUSO DE PODER ECONÔMICO COM FUNDAMENTO NO ART. 41-A DA LEI N. ${ }^{\circ}$ 9.504/97. OFERECIMENTO DE CIRURGIA DE LAQUEADURA, ENXOVAL E CESTA BÁSICA. GRAVAÇÃO AMBIENTAL DE CONVERSA DE ALEGADO OFERECIMENTO DE BENESSE EM TROCA DE VOTO. ATO PRATICADO POR FILHA DO CASAL (DE OITO/NOVE ANOS, QUE ESTAVA PRESENTE NA CONVERSAÇÃO) A QUEM FOI FEITO O ALEGADO OFERECIMENTO. PROVA ILÍCITA. CONTAMINAÇÃO DAS DEMAIS. INEXISTÊNCIA DE OUTRAS PROVAS A CORROBORAREM A DITA CORRUPÇÃO ELEITORAL. PARCIALIDADE DAS PESSOAS QUE FIZERAM A GRAVAÇÃO. INTERESSE DE ADVERSÁRIOS POLÍTICO, ORA RECORRENTES. ATO ILÍCITO QUE EXIGE A PROVA DIRETA, EFETIVA, CONCUSSA, SEGURA PARA EVENTUAL CONDENAÇÃO. DEPOIMENTOS TESTEMUNHAS FRÁGEIS. SENTENÇA DE IMPROCEDÊNCIA DA AÇÃO. 
MANUTENÇÃO. DESPROVIMENTO. [...] A Justiça Eleitoral deve, sempre, coibir as práticas nefastas que possam influenciar no livre exercício do sufrágio, até como meio de legitimar o exercício da representatividade política e de dar guarida e respeito à soberania popular a partir de um incólume processo eleitoral. No entanto, deve-se, sempre, pautar-se na garantia individual de aplicação de penalidades de forma razoável e proporcional, conforme os ditames constitucionais, valorando os fatos com a necessária ponderação jurídica. O reconhecimento fotográfico de acusado ou suposto autor do ilícito deve atender aos necessários requisitos previstos no art. 226 do Código de Processo Penal, bem como deve vir acompanhado e reforçado por outros elementos de prova que o corroborem.

Verificando-se que, mesmo após analisadas as captações ambientais, são insuficientes as provas carreadas aos autos para demonstrar a violação ao art. 41-A da Lei das Eleições, a qual exige prova inequívoca, escoimada de qualquer dúvida acerca da obtenção de voto com a utilização de vantagem ao eleitor, o que não se efetivou no caso dos autos, nega-se provimento ao recurso, confirmando-se o julgamento improcedente da ação.(RECURSO ELEITORAL nº 4041, Acórdão ${ }^{\circ}$ 8261 de 05/05/2014, Relator(a) HERALDO GARCIA VITTA, Publicação: DJE Diário da Justiça Eleitoral, Tomo 1044, Data 14/05/2014, Página 2/3, grifo nosso) (TRIBUNAL REGIONAL ELEITORAL DO MATO GROSSO DO SUL, 2014)

Com razão decidiu o Tribunal Mato-Grossense. A escolha de candidatos direcionada por vantagens econômicas ou políticas prejudica sobremaneira o desejável discurso democrático a ser travado no Poder Legislativo e, consequentemente, o auto reconhecimento da população como participante do processo de criação do ordenamento jurídico nacional.

HABERMAS (2012) faz uma associação direta entre a adoção do processo de formação legislativa racional e a sua teoria do discurso. Segundo o autor, a institucionalização do princípio do discurso acarreta na formação do princípio democrático que, por sua vez, confere legitimidade ao processo de criação normativa. Segundo o autor:

(...) Eu vejo esse entrelaçamento (entre o discurso e a formação do princípio democrático) como gênese lógica de direitos, a qual pode ser reconstruída passo a passo. Ela começa com a aplicação do princípio do discurso ao direito a liberdades subjetivas de ação em geral - constitutivo para a forma jurídica enquanto tal - e termina quando acontece a institucionalização jurídica de condições para um exercício discursivo da autonomia política, a qual pode equipar retroativamente a autonomia privada, inicialmente abstrata, com a forma jurídica. (HABERMAS, 2012, p. 158)

Nesse cenário, sendo o abuso de poder um instituto apto a afetar a representatividade dos cidadãos, pode-se entendê-lo como um potencial instrumento de prejudicialidade da sinceridade do discurso, interferindo não só no processo eleitoral, mas no próprio princípio democrático e nas condições para um exercício discursivo e adequado da autonomia política, até porque, nos regimes democráticos, a legitimidade do governante é elemento constitutivo do próprio Estado, conforme leciona MIRANDA (2007, p. 19): 
Para lá de ocasionais situações de facto baseadas no uso da força, nenhum governantes pode subsistir duradouramente se não for tido como legítimo pelos governados. Porque, como escreve Jellinek, o poder tem de assentar na convicção popular sobre a legitimidade. Esta aprovação, expressa de diversas maneiras e com mais ou menos vigor, é uma condição permanente na formação concreta do Estado e constitui uma das funções necessárias da comunidade popular como seu elemento constitutivo.

Não se trata só de adesão ou de consentimento de facto (que pode assumir diferentes graus, desde o meramente aclamatório às formas complexas de representação política). O problema da legitimidade é um problema de Direito, da ideia de Direito, de um conjunto de valores que, de uma forma ou de outra, liguem governantes e governados. (MIRANDA, 2007, p. 19).

Dessarte, o processo de desenvolvimento do Direito, quando legítimo e atento à racionalidade, se materializa em um processo circular onde o exercício livre e institucionalizado da autonomia política deságua ou, equipa retroativamente a autonomia privada e a própria formação dos direitos subjetivos que são assim reconhecidos quando os civis se autocompreendem não só como destinatários das leis, mas também como coparticipantes do processo legiferante.

Sabe-se que o Direito pressupõe a existência de relações sociais. Trata-se do reconhecimento pelo outro do direito alheio, em exata medida, cuja legitimidade fixa-se em uma dominação política, por meio da qual se escolhe livremente o que deve ser positivado. Consequentemente, a legitimidade de um direito subjetivo positivado guarda amparo no próprio sistema democrático de legiferação, ou seja, na soberania do povo que não pode ser atacada por interferências, como aquelas consubstanciadas no abuso de poder responsável por macular a democracia representativa.

Logo, como já tratado anteriormente, a fim de viabilizar o que se pode chamar de verificação objetiva da legitimidade e de existência de interferências negativas no procedimento de criação normativa, Habermas sugere que o direito preveja as condições sob as quais os civis possam julgar se o processo se deu de acordo com a racionalidade ou não. É justamente nesse contexto que se inserem os direitos fundamentais à participação nos processos de formação da vontade do legislador e os direitos políticos propriamente ditos (HABERMAS, 2012).

Nessa linha de raciocínio, HABERMAS (2012) destaca que os direitos políticos devem ser justamente aqueles capazes de fundamentar e de garantir a legitimidade do 
processo de inovação legislativa, que, por sua vez, se liga umbilicalmente ao conceito de liberdade comunicativa. Destaca o autor:

\begin{abstract}
Os direitos políticos procurados têm que garantir, por isso, a participação em todos os processos de deliberação e de decisão relevantes para a legislação, de modo que a liberdade comunicativa de cada um possa vir simetricamente à tona, ou seja, a liberdade de tomar posição em relação a pretensões de validade criticáveis. [...] Iguais direitos políticos fundamentais para cada um resultam, pois, de uma juridificação simétrica da liberdade comunicativa de todos os membros do direito; e esta exige, por seu turno, uma formação discursiva da opinião e da vontade que possibilita um exercício da autonomia política através da assunção dos direitos dos cidadãos. (HABERMAS, 2012, p. 164)
\end{abstract}

De fato, a ausência de liberdade e amplitude discursiva, põe em cheque a própria materialização do sistema representativo brasileiro e do pleito eleitoral, que constantemente, e talvez tradicionalmente, é atingido pela figura do abuso de poder de candidatos que acabam por influenciar a livre manifestação de vontade dos eleitores (voto) e a própria legitimidade dos mandatos entregues por meio da diplomação eleitoral.

Como se vê, ligando os conceitos habermasianos tangentes ao exercício da autonomia política ao tema eleitoral, torna-se claro que os efeitos do abuso de poder afetam o próprio senso de liberdade da população, que acaba por se sujeitar ao direcionamento de políticos que foram eleitos com base em emulações.

Afinal, um candidato que interfere na vontade do eleitorado por práticas como o uso indevido da máquina pública com finalidade eleitoreira - abuso de poder político - se eleito, certamente não estará representando ninguém além de seus próprios interesses, excluindo do discurso político estatal os seus eleitores, que deixarão de se reconhecerem como partícipes do processo de formação da vontade do estado.

A conclusão deriva do fato de que a teoria do discurso pressupõe ao princípio da democracia que os civis integrem de forma racional e participativa o processo de criação normativa o que é feito por meio da realização de eleições idôneas que reflitam a vontade popular. HABERMAS (2012) indica que:

O direito à positivação político autônoma do direito concretiza-se, finalmente, em direitos fundamentais, em direitos fundamentais que criam condições para iguais pretensões à participação em processos legislativos democráticos. Estes têm que ser instaurados com o auxílio do poder politicamente organizado. Além disso, a formação da vontade política organizada na forma do legislativo depende de um poder executivo em condições de realizar e implementar os programas acordados. $[\ldots]$ 
Tal dinâmica da auto-influência é acelerada através dos direitos de participação que fundamentam pretensões ao preenchimento de pressupostos sociais, culturais e ecológicos para um aproveitamento simétrico de direitos particulares de liberdade e de participação política. (HABERMAS, 2012, p. 171)

O trecho transcrito aponta a solução proposta pelo filósofo para o problema: a institucionalização do procedimento e dos direitos políticos, amparados pela força executória e sancionatória do Estado.

O autor acredita ser possível o uso do discurso positivado como garantia de legitimidade do discurso político e mais, como instrumento que dote a política de racionalidade. Em passagem didática de sua obra HABERMAS (2012) expõe o seu ideal:

Os direitos políticos de participação remetem à institucionalização jurídica de uma
formação pública da opinião e da vontade, a qual culmina em resoluções sobre leis e
políticas. Ela deve realizar-se em formas de comunicação, nas quais é importante o
princípio do discurso, em dois aspectos: O princípio do discurso tem inicialmente o
sentido cognitivo de filtrar contribuições e temas, argumentos e informações, de tal
modo que os resultados obtidos por este caminho têm a seu favor a suposição da
aceitabilidade racional: o procedimento democrático deve fundamentar a
legitimidade do direito. Entretanto, o caráter discursivo da formação da opinião e da
vontade na esfera pública política e nas corporações parlamentares implica,
outrossim, o sentido prático de produzir relações de entendimento, as quais são
"isentas de violência", no sentido de H. Arendt, desencadeando a força produtiva da
liberdade comunicativa.(HABERMAS, 2012, p. 191).

Com efeito, o direito é tido no texto como medium pelo qual se pode regulamentar e viabilizar o discurso amplo e sincero no bojo da sociedade, de forma a estabelecer a relação entre a concretude do direito e a própria aceitabilidade normativa.

Assim, é estabelecido ao Direito e a seus operadores a fiscalização e o banimento, por meio da instituição de regras e sanções, das interferências na liberdade comunicativa responsável por pautar o processo de formação democrática da vontade do Estado.

Sob essa ótica pode-se pensar em dois tipos de filtros procedimentais que podem ser institucionalizados com o intuito de garantir a livre participação e manifestação da população no processo democrático.

Os filtros preventivos se constituem em medidas legais cogentes dirigidas a impedir que o processo eleitoral como um todo possa ser maculado por condutas de candidatos e seus partidários. Trata-se de ferramenta que visa assegurar a gênese do sistema representativo, ou seja, as eleições.

Na legislação brasileira, o compilado de normas de Direito Eleitoral, juntamente com o aparato judicial composto pelo Poder Judiciário, o Ministério Público e as partes 
interessadas, fazem o papel dos filtros preventivos, que impedem, ou deveriam impedir, a influência na formação da vontade do eleitorado na escolha de seus representantes.

Como exemplo, pode-se citar o art. 41-A da Lei 9504/97, responsável por prever a ilegalidade da captação ilícita de sufrágio e a sanção a ela aplicada, consubstanciada na aplicação de multa e na cassação do registro ou diploma do candidato que tente comprar o voto alheio.

Como dito, referida norma, juntamente com outras previsões da Lei 9504/97, da CR/88 e da LC 64/90, têm por finalidade precípua impor aos atores do processo eleitoral a adoção de conduta hígida e apta a atrair legitimidade representativa e, consequentemente, a ampla participação dos eleitores no discurso político-administrativo de formação da vontade estatal, sendo possível aos Tribunais Eleitorais inclusive cassar os mandatos conferidos de forma emulativa aos candidatos transgressores e os afastar das disputas eleitorais por até oito anos. Nesse sentido já se manifestou o Tribunal Superior Eleitoral:

ELEIÇÕES 2012. VEREADOR. AGRAVO REGIMENTAL. RECURSO ESPECIAL. REPRESENTAÇÃO COM BASE NO ART. 41-A DA LEI N9.504/1997. CAPTAÇÃO ILÍCITA DE SUFRÁGIO. DISTRIBUIÇÃO DE VALES-COMBUSTÍVEL. PROVAS TESTEMUNHAIS E DOCUMENTAIS. CASSAÇÃO DE DIPLOMAS E MANDATOS POLÍTICOS. MULTA ELEITORAL. DESPROVIMENTO.

1. Não ocorrência de violação do art. $40, \S 2^{\circ}$, do CPC e do art. 22, incisos VI e VII, da $\mathrm{LC} \mathrm{n}^{\circ}$ 64/1990.

2. A configuração do ilícito previsto no art. 41-A da Lei $n^{\circ}$ 9.504/1997 exige a presença cumulativa dos seguintes requisitos: (i) realização de uma das condutas típicas previstas no dispositivo legal pelo candidato ou por terceiro, desde que, nessa hipótese, haja, ao menos, ciência do ilícito pelo favorecido; (ii) o fim especial de agir, consistente na vontade de obtenção do voto, embora não se exija a presença do pedido expresso. Esse entendimento se reforça com a edição da Lei Complementar $n^{\circ}$ 135/2010, pois o reconhecimento do ilícito em questão, além de ensejar a grave sanção de cassação de diploma, afasta o político das disputas eleitorais pelo longo prazo de oito anos (art. $1^{\circ}$, inciso I, alínea j, da $L C n^{\circ}$ 64/1990).

3. O conjunto probatório dos autos consistente em prova testemunhal coerente é apto a demonstrar o preenchimento de todos os requisitos da captação ilícita de sufrágio, sendo inviável o novo enquadramento jurídico dos fatos para fins de afastar as penalidades aplicadas.

4. Decisão agravada mantida por seus fundamentos. Agravo regimental desprovido. (Grifo nosso) (Agravo regimental no Agravo de Instrumento ${ }^{\circ}$ 49486, Pedra Preta/MT - TSE)

Por outro lado, os filtros repressivos devem ser entendidos como aqueles que servem a impedir que, após o pleito eleitoral, o discurso travado com o objetivo de formar a opinião 
política do Estado seja emulado, ou ainda, a garantir concretamente que os representantes do povo travem discursos temáticos racionais e não dirigidos a interesses estranhos ao público.

A institucionalização jurídica, no caso do filtro repressivo, passa inevitavelmente pelo chamado princípio parlamentar (HABERMAS, 2012). O autor indica que:

(...) o modo de escolha, o status dos deputados (imunidade, mandato livre ou não, formação de minorias), bem como o modo de decisão nas corporações (princípio da maioria, leituras repetidas), inclusive a organização do trabalho (formação de comissões), levantam questões de princípio. Estas têm que ser reguladas à luz do princípio do discurso, de tal modo que os pressupostos comunicativos necessários para discursos pragmáticos, éticos e morais, de um lado, e as condições de negociações equitativas, de outro lado, possam ser preenchidas satisfatoriamente. (HABERMAS, 2012, p. 214)

Além disso, o controle ou filtro repressivo pressupõe a independência harmônica entre o Poder Judiciário e o Poder Legislativo, isso para que haja um controle autônomo sobre a observância às garantias de adoção do discurso racional como meio pelo qual o processo legiferante transita. Nesse sentido:

\begin{abstract}
Esse tipo de discurso exige, de um lado, uma constelação de papéis, na qual os partidos (e, conforme o caso autoridades políticas mediadoras) podem apresentar todos os aspectos litigiosos de um caso a um juiz, como representante imparcial da comunidade; de outro lado, uma distribuição de competências segundo a qual o tribunal tem que fundamentar seu julgamento perante uma esfera pública jurídica, em princípio limitada. Ao passo que nos discursos de fundamentação há apenas participantes. De outro lado, a fim de impor suas decisões - e a execução do direito - a justiça apela para os meios de repressão do aparelho do Estado, passando a dispor, ela mesma de um poder administrativo. Por esta razão a justiça precisa ser separada da legislação e impedida de uma autoprogramação, Desta maneira se explica o princípio da ligação da justiça ao direito vigente. (HABERMAS, 2012, p. 216)
\end{abstract}

Como exemplo de controle ou filtro repressivo no Brasil tem-se o controle de constitucionalidade feito por meio de ações diretas de inconstitucionalidade, que visam basicamente desconstituir leis que não tenham observado o processo racional de sua formação (inconstitucionalidade formal) e aquelas que não exprimam de fato o desejo dos civis (inconstitucionalidade material). Referido exemplo é inclusive abordado pelo autor e coincide com as funções exercidas pelo Supremo Tribunal Federal como filtro repressivo:

Em princípio, qualquer ato administrativo, decretado ou recusado, pode ser transformado em objeto de uma ação anulativa, contestatória ou cominatória. Além disso, o tribunal constitucional abre para certos sujeitos de direito (eventualmente 
também para associações) que se sentem prejudicados pelas intervenções do executivo (ou por terceiros), o caminho do recurso constitucional (Verfassungsbeschwerde). (HABERMAS, 2012, p. 218)

Impede analisar, portanto, se o arcabouço jurídico vigente no Brasil é capaz de possibilidade a noção de democracia preconiza por Habermas.

\section{CONSIDERAÇÕES FINAIS: A INSUFICIÊNCIA DO MODELO VIGENTE}

A simples a institucionalização das mencionadas medidas preventivas e repressivas não são suficientes a concretamente impedir a emulação ou a influência negativa do abuso de poder na formação da vontade estatal.

Além da institucionalização de normas e de direitos, como os direitos políticos, o Estado precisa de força cogente e principalmente de garantir a autonomia entre os seus poderes, o que não se vê de forma efetiva no Brasil.

Sabe-se, por exemplo, que a CR/88, em seu art. 84, XIV, atribui ao chefe do poder executivo da União a nomeação dos Ministros do Supremo Tribunal Federal. Da mesma forma, o art. 119, II e o art. 120, $\S 1^{\circ}$, III da Carta Magna, atribuem ao presidente da república o poder de nomear dois dos sete magistrados que compõem os Tribunais Regionais Eleitorais dos estados e o próprio Tribunal Superior Eleitoral.

Assim, em apenas dois exemplos pode-se notar o excesso de interferência do poder executivo nas instituições que formam os filtros preventivos e repressivos dirigidos a combaterem a institucionalização do discurso político ilegítimo: os tribunais eleitorais, que aplicam as normas que combatem as interferências no processo eleitoral, são em parte formados por magistrados escolhidos pelo Presidente da República; da mesma forma, o Supremo Tribunal Federal, responsável por realizar o controle de constitucionalidade das leis aprovadas pelo poder legislativo, é integrado por membros também indicados pelo presidente da república.

A estrutura descrita não contribui para a proposta habermasiana de institucionalização objetiva de normas que promovam a adoção do discurso racional no processo político de formação da vontade pública.

Pelo exposto, nota-se que Habermas (2012), em sua obra Direito e Democracia, sugere a aplicação objetiva e institucionalizada do discurso como instrumento de garantia de legitimidade do processo de formação da vontade pública. 
O autor indica ainda que o processo adequado de adoção da racionalidade na política passa pela institucionalização do direito procedimental e dos direitos políticos dirigidos a garantirem a liberdade comunicativa e a ampla participação dos civis na criação das leis (autonomia pública) que, por sua vez, irão formar os direitos subjetivos (autonomia privada).

Para tanto, o presente artigo propõe a manutenção de filtros preventivos e repressivos aptos a garantirem, respectivamente, o afastamento de interferências negativas no processo eleitoral de escolha dos representantes da população e no próprio processo de criação normativa, mediante o controle de constitucionalidade formal e material.

No entanto, a adoção do sistema passa inevitavelmente por uma maior independência entre os poderes do Estado, principalmente pela autonomia do Poder Judiciário, a quem incube a aplicação das leis dirigidas a institucionalizar os filtros repressivos e preventivos descrito, o que não ocorre no Brasil atualmente.

Logo, a adoção do sistema racional de Habermas encontra ainda alguns obstáculos, que devem ser repensados e superados, a fim de que o sentimento de liberdade e de auto reconhecimento Kantiano volte a permear os civis brasileiros.

\section{REFERÊNCIAS}

AARNIO, Aulis. Essays on the Doctrinal Study of Law. Law and Philosophy Library.Kangasala. Finlândia, v. 96, p. 135. 2011. Disponível em https://books.google.com.br/books?id=QHXnqRKaHGkC\&pg=PR4\&lpg=PR4\&dq=doctrinal + study + of + law + aulis + aarnio\&source=bl\&ots=vIz2VADuq2\&sig=9YSfzUp8qULY4EbvzQcc WAedAUM\&hl=ptBR\&sa=X\&ved=0ahUKEwjIq76i2MrTAhXIQpAKHc16AmIQ6AEIPjAD $\# \mathrm{v}=$ onepage \&q=reasonable\&f=false. Acessado em 29/04/2017.

BRASIL. Tribunal Regional Eleitoral do Mato Grosso do Sul. Acórdão no 8261 no Recurso Eleitoral no 4041. Relator: VITTA, Heraldo Garcia: Publicado no DJE de 14/05/2014. Disponível em http://www.tre-ms.jus.br/jurisprudencia/jurisprudencia. Acessado em 26/04/2017.

BRASIL. Tribunal Superior Eleitoral. Acórdão proferido no Recurso Ordinário no 466997. Relator: MENDES, Gilmar Ferreira: Publicado no DJE de 03/10/2016. Disponível em http://www.tse.jus.br/jurisprudencia/pesquisa-de-jurisprudencia/jurisprudencia. Acessado em 03/05/2017.

BRASIL. Tribunal Superior Eleitoral. Acórdão proferido no Recurso Especial Eleitoral no 10070. Relator: BENJAMIN, Antonio Herman de Vasconcellos e: Publicado no DJE de 07/10/2016. Disponível em http://www.tse.jus.br/jurisprudencia/pesquisa-dejurisprudencia/jurisprudencia. Acessado em 03/05/2017. 
BRASIL. Tribunal Superior Eleitoral. Acórdão proferido no Agravo de Instrumento $\mathbf{n}^{\circ}$ 49486. Relator: MENDES, Gilmar Ferreira: Publicado no DJE de 17/03/2017. Disponível em http://www.tse.jus.br/jurisprudencia/pesquisa-de-jurisprudencia/jurisprudencia. Acessado em 03/05/2017.

CASTRO, Edson de Resende. Curso de Direito Eleitoral. $7^{\text {a }}$ edição. Belo Horizonte: Del Rey, 2014.

GOMES, José Jairo.Direito Eleitoral. 12a Edição. Belo Horizonte: Del Rey. 2016.

LUBENOW, Jorge Adriano. Esfera pública e democracia deliberativa em Habermas: modelo teórico e discursos críticos. Kriterion [online]; 2010, vo. 51, n.121, pp. 227-258. ISSN 0100-512X. Disponível em http://www.scielo.br/scielo.php?script=sci_arttext\&pid=S0100-512X2010000100012. 26/04/2017.

MALUF, Sahid. Teoria Geral do Estado. São Paulo: Saraiva, 2006.

MELLO, Celso Antônio Bandeira de. Discricionariedade e controle jurisdicional. $2^{\mathrm{a}}$ edição, $11^{\text {a }}$ tiragem. São Paulo: MALHEIROS, 2012.

Eficácia das normas constitucionais e direito sociais. $1^{\mathrm{a}}$ edição, $3^{\mathrm{a}}$ tiragem. São Paulo: Malheiros, 2011.

MIRANDA, Jorge. Formas e Sistemas de Governo. Rio de Janeiro: Forense, 2007.

HABERMAS, Jürgen. Direito e Democracia: entre facticidade e validade, vol. I. Rio de Janeiro: Tempo Brasileiro, 2012 - reimpressão.

HABERMAS, Jürgen. Três modelos normativos de democracia. In HABERMAS, Jürgen. A inclusão do outro. São Paulo: Loyola, 2004.

RIBEIRO, Fávila. Abuso de poder no Direito Eleitora. $3^{a}$ edição. Rio de Janeiro: Forense, 2001. 